\title{
Dimensional Study of Impacted Maxillary Canine Replicas 3D Printed Using Two Types of Resin Materials
}

\author{
RIHAM NAGIB ${ }^{1}$, CAMELIA SZUHANEK ${ }^{1 *}$, BOGDAN MOLDOVEANU², MEDA LAVINIA NEGRUTIU1', VIRGIL FLORIN DUMA ${ }^{3,4}$, \\ COSMIN SINESCU ${ }^{1}$, SILVIU BRAD ${ }^{1}$ \\ IVictor Babes University of Medicine and Pharmacy Timisoara, Faculty of Dental Medicine, 2 Eftimie Murgu Sq., 300041, \\ Timisoara, Romania \\ 2 MdentalStudio Dental Laboratory, Doctor Gheorghe Marinescu Str., 300092, Timisoara, Romania \\ 3 30M Optomechatronics Group, Aurel Vlaicu University of Arad, 77 Revolutiei Av., 310130, Arad, Romania \\ ${ }^{4}$ Politehnica University of Timisoara, 1 Mihai Viteazu Av., 300222, Timisoara, Romania
}

\begin{abstract}
3D printing paired with CBCT imaging technology could provide a more individualised approach to orthodontic diagnosis and tratment. The aim of the presentstudy is to asses dimensional differences between the CBCT image and 2 types of 3D printed replicas of an impacted maxillary canine, and to determine whether this method could be used in the future development of customised orthodontic attachments. Ten replicas were printed using the STL file of the impacted canine using two types of resin-five of each, with the same printer. Linear measurements of maximum height, length and width, were made. Mean dimensional erorrs were $0.184 \mathrm{~mm}$ and $0.068 \mathrm{~mm}$. The largest discrepancy was in lenght $-0.362 \mathrm{~mm}$. More reasearch is needed, but in this study we obtained printed resin replicas that provide sufficient dimensional accuracy to be used in orthodontics.
\end{abstract}

Keywords: orthodontics, replica teeth, $C B C T, 3 D$ printable resin

Imaging technologies used in dentistry are continiously evolving, changing orthodontics from diagnosis to treatment planning. 2D images used until recently are now being slowly replaced by cone bean computedtomography $3 \mathrm{D}$ volumes that offer a better and more complex view of the airway, bone and tooth structures. Higher confidence in diagnosis accuracy and treatment planning appears when clinicians are confronted with CBCT images, especially in imapaction cases [1]. Studies have shown that the use of CBCT data using voxel sizes of 0.25 and $0.4 \mathrm{~mm}$, provides a good basis for the production of replicas for diagnostic and treatment planning use in both orthodontics and dentistry [2].

Additive manufacturing technologies are already altering clinical approches in fields like prosthodontics, maxillofacial surgery, endodontics. In years to come orthodontics is also expected to benefit from this versatile technique, paired with CBCT and intraoral scanning,and provide a more individualised approach to tratment possibilities and even 3D printed custom made components [3-5].

The aim of the present study is to asses dimensional differences between the CBCT image and 2 types of 3D printed photopolymeric resin replicas of an impacted maxillary canine, and to determine whether this method of tooth replication could be used in the future development of customised orthodontic attachments.

Improvements in 3D printing and its mainstream availability made the use of replica teeth easier. Gok et. al use models of mandibular molars to compare endodontic filling techniques [6]. Autotransplantation using replicas of donor teeth has the potential to provide an alternative that could make the procedure easier and with a more predictible outcome [7,8]. In the complex case of a type 3 dens invaginatus mentioned by Kfir et al., model teeth facilitated the trial of different treatment scenarios and made a conservative approach possible [9] .

\section{Experimental part}

A cone beam computed tomography volume voxel size 0.25 mmof an unilateral maxillary impaction case was segmented and the impacted cuspid was extracted and cleaned. The DICOM data was transformed into a STL file and imported to a CAD software (fig. 1.)

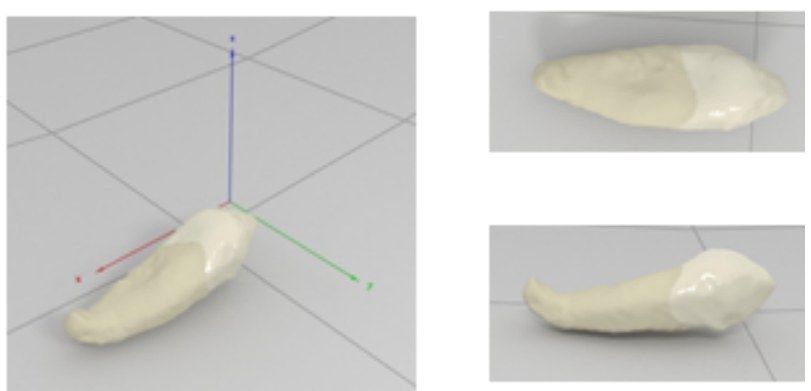

Fig. 1. Rendered images of the impacted canine in CAD software - subjective crown delimitation din not influence the dimensional values

Maximum dimensions of the virtual model tooth were obtained through linear measurements of height, length and width. Replica teeth of the impacted canine were produced with the Form2 (Formlabs Inc., USA) 3D printer. Two kinds of resin material were used : NextDent $C \& B$ (Vertex-Dental, Netherlands) - class 2a biocompatible resinand Clear FLGPCL03(Formlabs Inc.,USA)photopolymeric resin. Five copies of each type were printed at $0.025 \mathrm{~mm}$ and were diveded in group $\mathrm{A}$ (biocompatible resin) and group $B$ (clear resin). The supporting structure was broken off and the remaining material polished with soft straight handpiece burs (fig. 2)

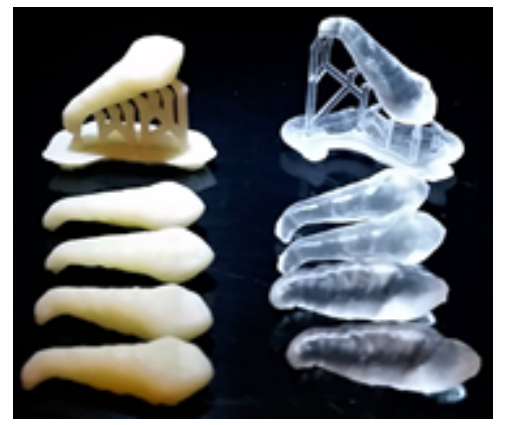

Fig. 2. Group A resin replicas(left)and group $B$ resin replicas(right), with and without supporting structure 


\begin{tabular}{|c|c|c|c|c|c|c|}
\hline & \multicolumn{3}{|c|}{ Group A } & \multicolumn{3}{c|}{ Group B } \\
\cline { 2 - 7 } & Max. lenght & Max. width & Max. height & Max. lenght & Max. width & Max. height \\
\hline 1 & 22.92 & 7.87 & 7.35 & 23.44 & 7.97 & 7.51 \\
\hline 2 & 22.89 & 7.70 & 7.35 & 23.30 & 7.94 & 7.53 \\
\hline 3 & 22.84 & 7.85 & 7.35 & 23.33 & 7.96 & 7.52 \\
\hline 4 & 22.89 & 7.88 & 7.37 & 23.37 & 7.96 & 7.49 \\
\hline 5 & 22.95 & 7.77 & 7.38 & 23.30 & 7.95 & 7.50 \\
\hline
\end{tabular}

Table 1

DIMENSIONAL VALUES FOR THE 10 STUDIED SAMPLES FROM GROUP A AND GROUP B

The resulting replicas were measured in order to obtain their maximum dimensions, as was done with the virtual model. Points were drawn to provide the same measurments as for the virtual model. An observer measured the replica teeth twice at an one week interval using a stainless steel digital caliper.

\section{Results and discussions}

Virtual measurements of the model tooth provided values as follows : $23.26 \mathrm{~mm}$ maximum lenght, $7.86 \mathrm{~mm}$ maximum width and $7.54 \mathrm{~mm}$ maximum height. Values of the physical measurements of the ten 3D printed replica teeth are presented in table 1.

The mean value of all five measurements was taken into consideration when compared with the virtual dimension of the STL file used for 3D printing. Mean values for group A were $22.898 \mathrm{~mm}$ maximum lenght, 7.814 maximum width and 7.36 maximum height. Mean values for group B were $23.348 \mathrm{~mm}$ maximum lenght, $7.956 \mathrm{~mm}$ maximum width, $7.51 \mathrm{~mm}$ maximum height.

Dimensional discrepancies found regarding heightwere $0.08 \mathrm{~mm}$ betwen the virtual model and group $B$ replicas, and $0.362 \mathrm{~mm}$ between the virtual model and the group Asamples. The biocompatible resin replica teeth were smaller than the virtual model while the clear resin ones were slightly larger. Width difference was $0.046 \mathrm{~mm}$ between the virtual model and group A and $0.096 \mathrm{~mm}$ for group $B$. Height difference compared to the virtual model was $0.18 \mathrm{~mm}$ for group $A$ and $0.03 \mathrm{~mm}$ for group B.Mean dimensional erorrs of the replica teeth were $0.184 \mathrm{~mm}$ group $A$, and $0.068 \mathrm{~mm}$ - group $B$.

Studies comparing the production of replica teeth using different printing technologies reported similar dimensional errors as the present study. Comparing the STL reference files, the Poly] et, stereolithography and fused deposition modeling replicas showed significantstatistical differences in some studies, but the differences were regarded as clinically insignificant. Observed dimensional error varied from $0.127 \mathrm{~mm}$ to $0.047 \mathrm{~mm}, 0.038 \mathrm{~mm}[10,11]$.

Printed orthodontic models are also a point of interest regarding dimensional accuracy and stability. Significant reductions compared to the plaster models were observed especially in the transverse plane $[12,13]$. Hassan et al. concluded that rapid prototyping models of orthodontic crowding patients were not clinically comparable with conventional stone models [14].

Material, data aquisition technique, 3D printing technology are all factors of influence when it comes to dimensional accuracy $[17,18]$. Aside from the factors above, there is also the build angle and support structure configuration that can have a significant influence on the resulting printed model [15]. Osman et.al recommends a buiding angle of 135 degrees when using a digital light processing system [16].

\section{Conclusions}

3D printed resin replicas of impacted teeth provide sufficient dimensional accuracy to be used in orthodontics for different purposes.Although it has been around for decades, 3D printing in now becoming more accesible and along with its evolution more reaserch regrading dimensional accuracy and materials will be needed.

\section{References}

1. HANEY, E.,GANSKY, S.A., LEE, J.S., J OHNSON, E., MAKI, K., MILLER, A.J., HUANG, J.C.,American J ournal of Orthodontics and Dentofacial Orthopedics 2010, 137(5), 590-597.

2. PRIMO, B.T., PRESOTTO, A.C.,DE OLIVEIRA, H. W., GASSEN, H.T., MIGUENS, S.A.Q., SILVA, A.N., HERNANDEZ,P.A.G., International J ournal of Oral and Maxillofacial Surgery 2012, 41(10), 1291-1295.

3. STANSBURY, J.W., IDACAVAGE, M.J .,Dental Materials 2016, 32(1), $54-$ 64.

4. JHEON, A.H.,OBEROI, S., SOLEM, R.C., KAPILA, S.,Orthodontics \& Craniofacial Research 2017, 20, 106-113.

5. BARAZANCHI, A., LI, K.C., AL-AMLEH, B., LYONS, K., WADDELL,J.N., Journal of Prosthodontics-Implant Esthetic and Reconstructive Dentistry 2017, 26(2), 156-163.

6. GOK, T., CAPAR, I. D., AKCAY, I., KELES,A., J ournal of Endodontics 2017, 43(9), 1559-1564.

7. MOIN,D.A.,VERWEIJ , J.P., WAARS,H., VAN MERKESTEYN, R., WISMEIJER,D., J ournal of Oral and Maxillofacial Surgery 2017, 75(5). 8. VERWEIJ , J .P., MOIN, D.A., WISMEIJ ER,D.,VAN MERKESTEYN, J.P.R., J ournal of Oral and Maxillofacial Surgery 2017, 75(9), 1809-1816.

9. KFIR, A., TELISHEVSKY-STRAUSS, Y., LEITNER, A., METZGER, Z., International Endodontic J ournal 2013, 46(3), 275-288.

10. DIETRICH, C.A., ENDER,A., BAUMGARTNER, S., MEHL, A., Angle Orthodontist 2017, 87(5), 782-787.

11. LEE, K.I., CHO, J.W., CHANG,N.Y., CHAE, J.M., KANG, K.H., KIM, S.C., CHO, J.H., Korean J ournal of Orthodontics 2015, 45(5), 217-225. 12.CAMARDELLA, L.T., VILELLA, O.D.V.,BREUNING, H., American Journal of Orthodontics and Dentofacial Orthopedics 2017, 151(6), 1178-1187.

13.CAMARDELLA, L.T., VILELLA, O.V., VAN HEZEL, M.M., BREUNING,K.H., Journal of Orofacial Orthopedics-Fortschritte Der Kieferorthopadie 2017, 78(5), 394-402.

14. HASSAN, W.N.W., YUSOFF, Y., MARDI, N.A.,American J ournal of Orthodontics and Dentofacial Orthopedics 2017, 151(1), 209-218.

15. ALHARBI, N., OSMAN, R.B., WISMEIJER, D.,International Journal of Prosthodontics 2016, 29(5), 503-510.

16. OSMAN, R.B.,ALHARBI, N.,WISMEIJ ER,D., International J ournal of Prosthodontics 2017, 30(2), 182-188.

17. SZUHANEK, C., GRIGORE, A., SCHILLER, E., BRATU, D.C., ONISEI, D.,ONISEI, D., The Role of Digital Setup in the Orthodontic Treatment with Plastic Aligners. Mat.Plast,,52, no. 4, 2015 , p.522

18. SZUHANEK, C., JIANU, R., CIRCIUMARU, L., NEGRUTIU, M., SINESCU, C., CLONDA, C.S., SCHILLER, E.,POPA, A.,GRIGORE,A., Microstructural Changes in Orthodontic Archwires after Alternative Bending Techniques. Rev.Chim.(Bucharest), 67, no. 11, 2016, p.2363. 